\title{
Experimental Study of Backdraft in a Compartment with Different Opening Geometries and its Mitigation with Water Mist
}

\author{
WENGUO WENG and WEICHENG FAN \\ State Key Laboratory of Fire Science \\ University of Science and Technology of China \\ Hefei, Anhui, 230026, P.R. China
}

\begin{abstract}
This paper presents the results of reduced-scale experimental tests to study backdraft in a reduced-scale compartment $(1.2 \mathrm{~m} \times 0.6 \mathrm{~m} \times 0.6 \mathrm{~m})$, fitted with six end opening geometries and two ceiling opening geometries. The experimental variables included the fuel flow rate, the time during which the fuel was burned, and the opening geometries. The quantities recorded before backdraft included temperature and the concentrations of oxygen, carbon dioxide, and carbon monoxide. To quantify the effect of backdraft, the gas velocities in the opening and also the pressures in the compartment were measured. The effects of different opening geometries on the occurrence of backdraft are discussed. This study shows that the mass fraction of unburned fuel (i.e., the unburned methane in this study), whose critical value varies with the opening geometry, is a key parameter determining the occurrence of backdraft. In addition, the experimental results using water mist, generated by a downward-directed pressure nozzle that was operated at pressure of $0.2 \mathrm{MPa}$, to mitigate backdraft are presented. The experimental results show that water mist is an effective mitigating tactic able to suppress backdraft in a compartment primarily by means of diluting the gas in the compartment and reducing the mass fraction of unburned fuel, rather than by a thermal mechanism of cooling.
\end{abstract}

KEY WORDS: backdraft, water mist, compartment fire, opening geometry

\section{INTRODUCTION}

During fires in a building with limited ventilation, backdraft may develop that can produce fire gases containing significant proportions of partial combustion products and un-burnt pyrolysis products. If these accumulate, when an opening is made to the building and air enters, it can lead to a sudden deflagration. The deflagration moving through the building and out of the opening is a backdraft. Backdraft continues to be a hazard that can kill people and cause the building to collapse [1-2].

Little research has been done on backdraft. Fleischmann [2-5] conducted experiments in a half-scale compartment with two opening geometries and methane as fuel. Full-scale 
experiments have been conducted by Bolliger [6] to determine the effect of scaling the compartment; the results were compared with Fleischmann's work [2]. Gojkovic et al. [7] used natural gas as fuel to study backdraft in a compartment (5.2 m x $2.2 \mathrm{~m} \times 2.2 \mathrm{~m}$ ). Full-scale backdraft experiments have also been performed [8-10] in two different compartments to improve naval firefighting tactics using Diesel spray as fuel. One compartment was used to produce safe and reliable backdraft scenarios, which could be used as a basis for conducting backdraft experiments onboard a ship. Another compartment with different geometries and ventilation conditions was adjacent to the backdraft compartment. They [8-10] also tried to prevent backdraft using a water spray.

Weng carried out experimental and theoretical study on backdraft in a compartment for his Ph. D degree supervised by Prof. Fan, and published some journal papers. Weng and Fan [11-12] established a reduced-scale apparatus to study the critical condition of the occurrence of backdraft and the effects of different opening geometries on backdraft. Water mist was applied to mitigate backdraft [13-14]. In theory analysis, a model of backdraft was established and the nonlinear dynamical mechanism of backdraft was analyzed [15], and numerical models including a subgrid scale laminar flamelet model and a partially premixed model are imbedded in FDS3.0 source code for backdraft simulation [16]. In order to investigate the gravity current prior to backdraft, a series of scaled salt water experiments using flow visualization and DPIV (Digital Particle Image Velocimetry) were conducted [17]. This paper presents experimental results extracted from Weng's dissertation in Chinese [18].

\section{EXPERIMENTAL DESIGN AND PROCEDURE}

The configuration of the backdraft apparatus is given in Fig. 1. The apparatus is made up of a reduced-scale compartment, fuel system, ignition system, water mist system, data acquisition system. These systems are described in detail in the following section.

A special compartment was constructed to withstand the dangerous overpressures expected in backdrafts. The experimental apparatus (1.2 $\mathrm{m}$ x $0.6 \mathrm{~m}$ x $0.6 \mathrm{~m})$ was roughly $1 / 4$ that of a residential room to minimize this hazard and to carry out backdraft experiments more precisely. Because of the explosive nature of backdrafts, the internal and external surfaces of the compartment were totally covered with $2 \mathrm{~mm}$ thick stainless steel, welding together to ensure strength. The filler between the two layers of stainless steel was a refractory aluminosilicate blanket (200 mm thick), whose thermal conductivity was $0.36 \mathrm{~W} / \mathrm{mK}$ at $1200 \mathrm{~K}$, to provide the primary thermal resistance for the structure. An observation window (quartz glass, $0.45 \mathrm{~m}$ high by $0.75 \mathrm{~m}$ wide, capable of withstanding $1200 \mathrm{~K}$ and $10 \mathrm{kPa}$ ) was installed in one of the long walls. In one of the 
short walls and ceiling, shown in Fig. 2, bolt holes were built so that different opening geometries, shown in Fig. 3, could be easily modified by replacing a face plate bolted to the compartment. These end and ceiling openings were covered with a computer-activated hatch, which was opened after the fire had been burning for a predetermined time. The angular speed of the hatch was $\sim 45^{\circ} /$ s. Every effort was made to seal all the construction holes to control leakage.

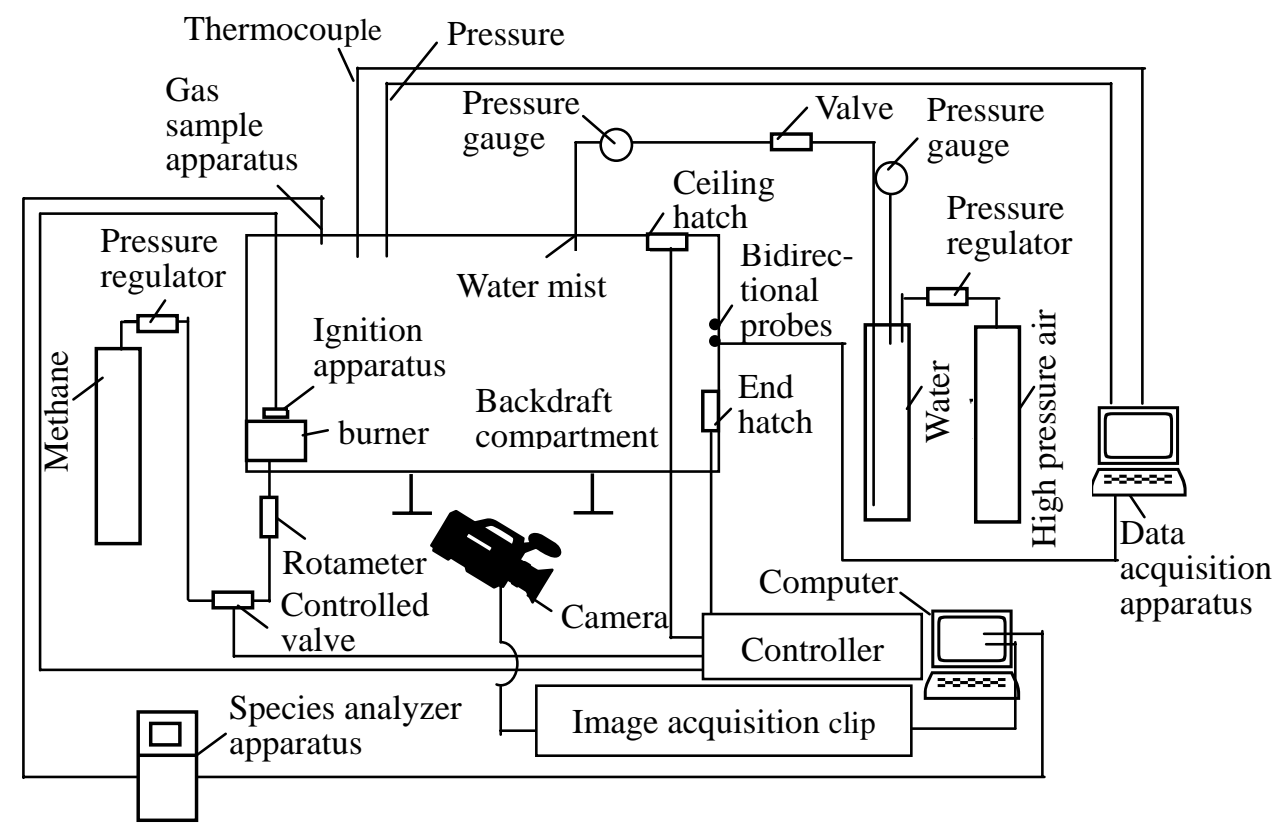

Fig. 1. Schematic of the backdraft experimental apparatus.

A methane ( $99.8 \%$ pure) burner ( $0.15 \mathrm{~m}$ square by $0.15 \mathrm{~m}$ high) was placed against the wall opposite to that with the openings, as in Fig. 1. To ignite the combustible mixture in the compartment, an electrically heated metal wire (power $1200 \mathrm{~W}$ ) provided an ignition source. The wire was $0.6 \mathrm{~m}$ long and was round around a ceramic cylinder (diam. $0.05 \mathrm{~m}$ ), which was horizontally fastened on the burner.

A downward-directed pressure nozzle 212.285 (from Lechler GmbH \& Co. KG) was positioned $0.3 \mathrm{~m}$ from the wall with the openings, $0.078 \mathrm{~m}$ from the ceiling, and $0.3 \mathrm{~m}$ from the wall with the observation window. High pressure air was combined in the water tank so the water can be crushed into millions of water droplets, and this way water mist was formed. The nozzle was operated at a pressure of $0.2 \mathrm{MPa}$ in this work. The water sprays were injected directly downward into the compartment and the cone angel of the nozzle was $60^{\circ}$. The flow rate was about $3.0 \mathrm{ml} / \mathrm{s}$, and the volume mean diameter of the mist was about $38 \mu \mathrm{m}$, measured using a LDV/APV (Laser Doppler Velocimeter/ 


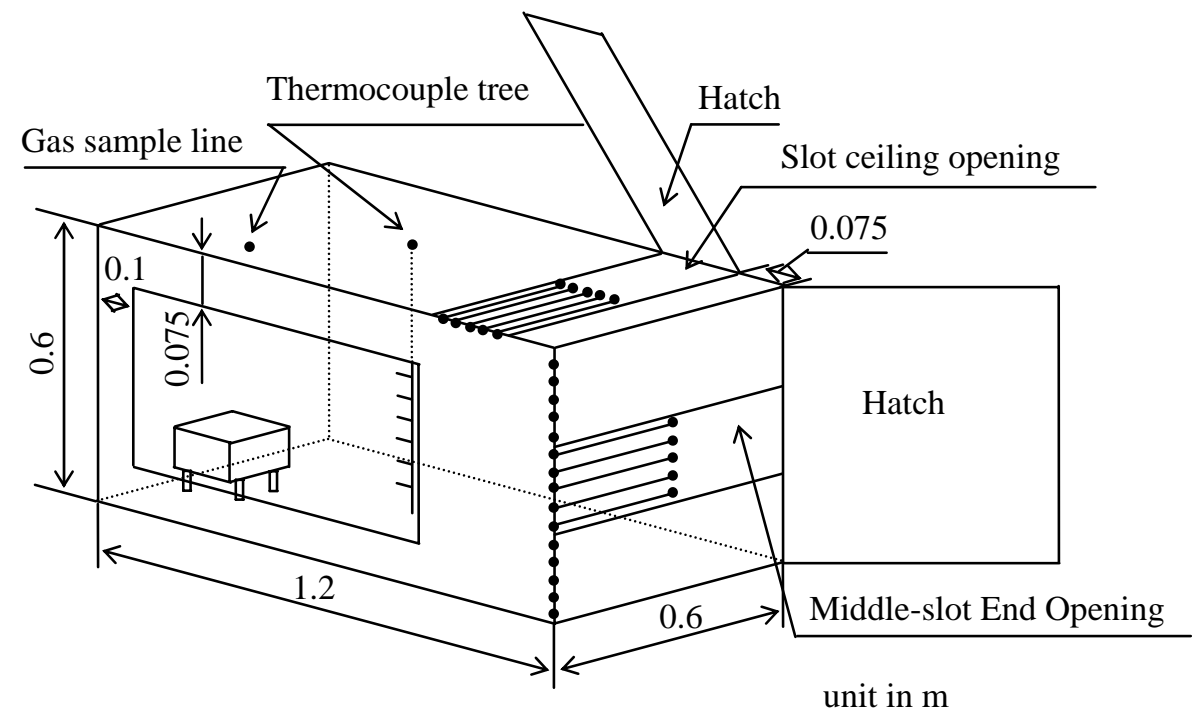

Fig. 2. Sketch of the reduced-scale compartment giving the internal dimensions of the compartment and the locations of the instrumentation.

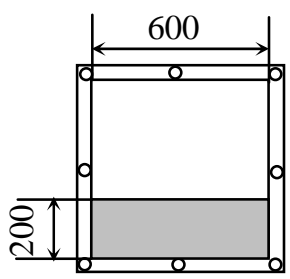

Downside-slot end opening

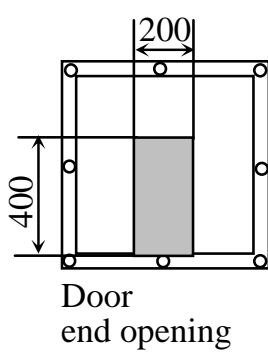

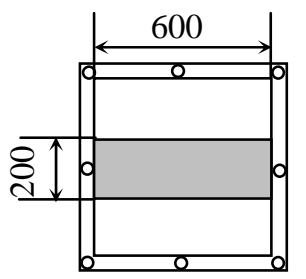

Middle-slot end opening

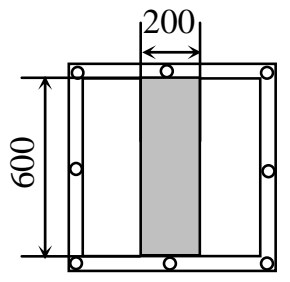

Vertical middle-slot end opening

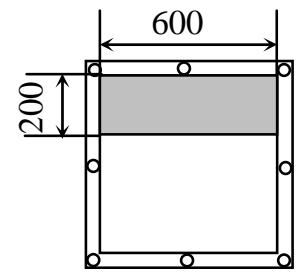

Upside-slot end opening

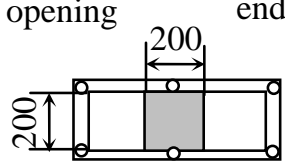

Window ceiling opening

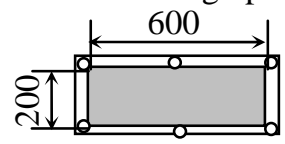

Slot ceiling opening unit in $\mathrm{mm}$

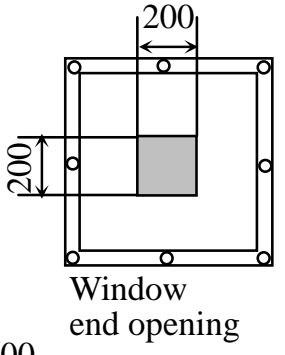

Fig. 3. Sketch of eight opening geometries for the reduced-scale compartment.

A vertical tree of thermocouples was placed through the middle of the ceiling. The thermocouples were made from $0.2 \mathrm{~mm}$ type $\mathrm{K}$ thermocouple wire with a stainless steel overbraid. The average bead diameter was $1 \mathrm{~mm}$. The ten thermocouples were located at 
$0.05 \mathrm{~m}$ intervals, with the highest thermocouple at $0.075 \mathrm{~m}$ below the ceiling. The thermal interface height history was calculated from the time dependent temperature profiles recorded from the thermocouple tree. The profiles were converted into the average upper and lower layer temperatures using the method of Quintiere, et al. [19] applied to steady state temperature profiles. The pressure in the compartment was recorded using an electronic pressure transducer (NOVA technique) whose calibrated range was -150 to $300 \mathrm{~Pa}$, and response time was $500 \mu \mathrm{s}$. The pressure pot was placed $0.3 \mathrm{~m}$ from the wall with the openings and mounted in the wall opposite to the observation window at floor level. The ambient pressure reference was taken outside the compartment. The flow rate of methane was measured by a rotameter with an effective range of 160 to $1600 \mathrm{~L} / \mathrm{h}$. The uncertainty in this measurement was estimated to be $1 \%$ based on a flow test of the system. The mass of water mist was calculated from the pressure, measured by a manometer with an effective range of 0-1 MPa, and diameter $(15.4 \mathrm{~mm})$ of water pipeline. The uncertainty was estimated to be $1.5 \%$ based on a standard test.

Continuous gas samples for measuring the concentrations of $\mathrm{O}_{2}, \mathrm{CO}_{2}$ and $\mathrm{CO}$ were taken through a stainless steel sampling tube, located $0.9 \mathrm{~m}$ from the wall with the openings, $0.1 \mathrm{~m}$ from the ceiling, and $0.1 \mathrm{~m}$ from the wall with the observation window. Analyzers consisted of SIEMENS ULTRAMAT 23 for $\mathrm{CO}_{2}$ (25\% mass full-scale range), $\mathrm{O}_{2}$ (25\% mass full-scale range) and SIEMENS ULTRAMAT 22 for CO (3\% mass full-scale range). Unburned fuel $\left(\mathrm{CH}_{4}\right.$ in this study) could be calculated based on the equation for oxidation. The following assumptions were necessary: (1) that the upper layer was well-stirred, and (2) that the overall reaction was:

$\mathrm{CH}_{4}+a\left(\mathrm{O}_{2}+3.77 \mathrm{~N}_{2}\right) \rightarrow b C \mathrm{O}_{2}+c \mathrm{CO}+d \mathrm{H}_{2} \mathrm{O}+e \mathrm{~N}_{2}+f \mathrm{fH}_{4}$

Using these assumptions, which were reasonable since the fire source was a methane gas burner, an overall balance on the oxygen and carbon would yield the concentration of unburned fuel.

$Y_{F}=m_{\mathrm{CH}_{4}} / m_{\text {total }}-(4 / 11) Y_{\mathrm{CO}_{2}}-(4 / 7) Y_{\mathrm{CO}}$

Here $m_{\mathrm{CH}_{4}}$ is the total mass which has entered the compartment and $m_{\text {total }}$ is the total mass of gas in the compartment. $Y_{F}, Y_{\mathrm{CO}_{2}}, Y_{\mathrm{CO}}$ are the mass fractions of unburned fuel, carbon dioxide, and carbon monoxide, respectively.

The flow in and out of the compartment after the hatch was opened was recorded using 10 bidirectional probes in the opening. The probes (diam. $15 \mathrm{~mm}$ ) were designed in accordance with the guidelines given by McCaffrey et al. [20]. The probes were located in the center of the opening as shown in Fig. 1 and were $37.5 \mathrm{~mm}$ apart for all the opening geometries, except the vertical middle-slot end opening, where the probes were 
$75 \mathrm{~mm}$ apart, and the top and bottom probes were $37.5 \mathrm{~mm}$ from the soffit and sill, respectively. The pressure difference between the gases in the compartment and the air outside the compartment was measured using a differential pressure transducer (NOVA technique) whose calibrated range was $\pm 300 \mathrm{~Pa}$, and response time was $200 \mu \mathrm{s}$. The mass flow rate through the opening can be calculated using the data measured by the bidirectional probes and the relationship given before [2].

Data from the thermocouple, pressure transducer and differential pressure transducer were recorded using HP E1413 with a 64-channel high-speed scanning Analog-to-Digital Converter. The system was capable of recording each channel $10^{5}$ times a second. Video data were captured using Panasonic DS28, which had 25 frames per second. The length and height of fire ball which burns outside the compartment would be measured according to these video data.

Before each experiment, a 60s base line was taken to record the initial conditions. The burner was left on and the flame was ignited using the electrically heated metal wire before the start of the experiment. At 0s, the hatch was closed. After a predetermined time period (the flow time of the fuel), the gas flow to the burner was terminated immediately when the hatch was opened. During this time period, the fire would be from combustion to extinction due to insufficient oxygen. After the hatch was opened, the metal wire would ignite the combustible mixture in the compartment if ignition was reached. At the end of the experiments, the metal wire was taken off.

\section{EXPERIMENTAL RESULTS AND DISCUSSIONS}

\section{Critical Condition of Backdraft}

64 backdraft experimental results for eight opening geometries of the downside-slot end opening, the middle-slot end opening, the upside-slot end opening, the window end opening, the door end opening, the vertical middle-slot end opening, the window ceiling opening and the slot ceiling opening are seen in Ref. [18]. Table 1, taken as an example, is a summary of the backdraft experiments in the reduced-scale compartment with the door end opening. Here $T_{a}$ is the ambient temperature. $Y_{\mathrm{O}_{2}}, Y_{\mathrm{CO}_{2}}, Y_{\mathrm{CO}}$ and $Y_{F}$ are the mass fractions of oxygen, carbon dioxide, carbon monoxide and unburned fuel at hatch opening, respectively. $T_{U}, T_{L}$ and $h_{L}$ are the upper temperature, the lower temperature and the layer height at hatch opening, respectively. $P_{\max }$ is the peak pressure measured inside the compartment at hatch opening. $m_{\text {in }}^{t=t_{i}}, m_{\text {out }}^{t=t_{i}}, m_{\text {in }}^{t=t_{f_{0}}}$, $m_{\text {out }}^{t=t_{\text {fo }}}$ are the total mass which flows into and out of the compartment after hatch opening and prior to ignition, and that after hatch opening and prior to flames exiting 


\begin{tabular}{|c|c|c|c|c|c|c|c|c|c|}
\hline 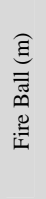 & 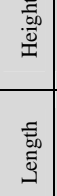 & $\underset{\mathrm{i}}{\mathrm{i}}$ & 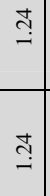 & 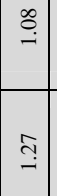 & $\stackrel{9}{\rightarrow}$ & \begin{tabular}{|c|}
$\stackrel{0}{0}$ \\
\hdashline \\
0
\end{tabular} & ה. & gi & 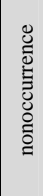 \\
\hline \multirow{4}{*}{ 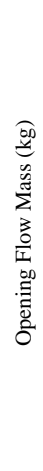 } & $\overbrace{\tilde{I}}^{\mathbb{I}}=$ & $\mid \begin{array}{l}0 \\
0 \\
0 \\
0\end{array}$ & 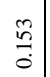 & $\mid \begin{array}{l}\stackrel{9}{7} \\
0 \\
0\end{array}$ & त् & 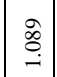 & $\begin{array}{l}0 \\
\substack{0 \\
0}\end{array}$ & 冚 & : \\
\hline & $\stackrel{0}{\mathbb{I}}=$ & $\begin{array}{l}0 \\
\stackrel{0}{0} \\
0\end{array}$ & $\stackrel{\widehat{\imath}}{0}$ & $\mid$ & $\begin{array}{l}0 \\
\stackrel{1}{0} \\
0\end{array}$ & \begin{tabular}{|l|}
0 \\
0 \\
0 \\
0
\end{tabular} & $\mid \begin{array}{l}\tilde{c} \\
0 \\
0 \\
0 \\
0\end{array}$ & $\stackrel{\text { 恿 }}{0}$ & 芯 \\
\hline & $\stackrel{\mathbb{I}}{\Xi}$ & $\begin{array}{l}\overrightarrow{\mathrm{g}} \\
\dot{0}\end{array}$ & $\begin{array}{l}\vec{\Xi} \\
\dot{0}\end{array}$ & $\begin{array}{l}\hat{7} \\
0\end{array}$ & $\begin{array}{l} \pm \\
\stackrel{0}{0} \\
0\end{array}$ & $\mid$\begin{tabular}{l|}
0 \\
\multirow{7}{0}{} \\
0
\end{tabular} & $\begin{array}{l}0 \\
0 \\
0 \\
0\end{array}$ & $\stackrel{0}{\circ}$ & ฮิ \\
\hline & $\tilde{E}$ & $\begin{array}{l}0 \\
\stackrel{m}{0} \\
0\end{array}$ & $\stackrel{\overrightarrow{7}}{\stackrel{0}{0}}$ & $\begin{array}{l}7 \\
7 \\
0\end{array}$ & \begin{tabular}{ll}
$\stackrel{2}{2}$ \\
\hdashline \\
0
\end{tabular} & $\left|\begin{array}{l}0 \\
\vdots \\
0 \\
0\end{array}\right|$ & $\begin{array}{l}0 \\
\tilde{o} \\
0 \\
0\end{array}$ & $\stackrel{\stackrel{2}{7}}{\circ}$ & 范 \\
\hline \multicolumn{2}{|r|}{ ఏ } & $\begin{array}{l}\tilde{\sigma} \\
\tilde{\sim}\end{array}$ & 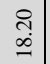 & $\mid$\begin{tabular}{|l}
$\mid \vec{A}$ \\
$\stackrel{-}{-1}$
\end{tabular} & 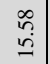 & 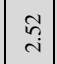 & స్ల & $\stackrel{8}{9}$ & न्: \\
\hline \multirow{3}{*}{ 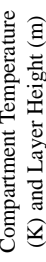 } & $=$ & 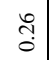 & 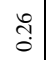 & $\begin{array}{c}\hat{y} \\
0\end{array}$ & ָ̊. & $\left|\begin{array}{c}\infty \\
\hdashline \\
0\end{array}\right|$ & ¿্రి & సָ & స్ \\
\hline & $\mathrm{H}$ & 品 & 峞 & $\begin{array}{c} \pm \\
m \\
m\end{array}$ & 踚 & 瓜 & $\stackrel{m}{m}$ & $\stackrel{m}{m}$ & 足 \\
\hline & $\rightarrow$ & $\begin{array}{l}\stackrel{2}{2} \\
\stackrel{m}{m}\end{array}$ & 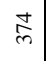 & 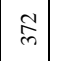 & 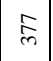 & 命 & 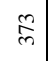 & $\stackrel{m}{m}$ & 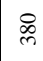 \\
\hline \multirow{4}{*}{ 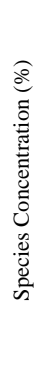 } & $\lambda^{4}$ & $\begin{array}{l}\hat{n} \\
\dot{f}\end{array}$ & 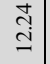 & 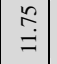 & 导 & $\mid \begin{array}{c}\tilde{a} \\
\stackrel{\alpha}{\alpha} \\
\propto\end{array}$ & 苟 & $\begin{array}{c}\qquad \\
\infty \\
\infty\end{array}$ & $\overrightarrow{0}$ \\
\hline & $i^{8}$ & 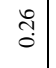 & @్రి & 产 & : & $\mid$ & 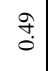 & 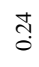 & 号 \\
\hline & $>^{8}$ & $\stackrel{\leftrightarrow}{\rightarrow}$ & 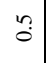 & $\mid$ & : & $\mid \begin{array}{l}\infty \\
0\end{array}$ & $\stackrel{\infty}{\circ}$ & 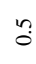 & $\stackrel{t}{0}$ \\
\hline & $\lambda^{\circ}$ & $\stackrel{\circ}{\dot{f}}$ & $\stackrel{L}{\underset{\sim}{ \pm}}$ & 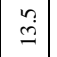 & 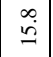 & $\begin{array}{l}0 \\
\dot{ \pm}\end{array}$ & 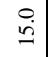 & $\stackrel{L}{\leftrightarrow}$ & : \\
\hline \multicolumn{2}{|c|}{ 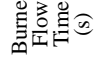 } & 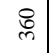 & ి & \begin{tabular}{|l|} 
多 \\
\end{tabular} & ヲ & $\begin{array}{l}\text { O } \\
\end{array}$ & 亭 & స్లి & $\stackrel{\infty}{\sim}$ \\
\hline \multicolumn{2}{|c|}{ 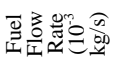 } & 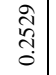 & 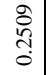 & 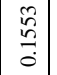 & $\begin{array}{c}0 \\
0 \\
0 \\
0 \\
0\end{array}$ & $\left|\begin{array}{c}0 \\
0 \\
0 \\
0 \\
0\end{array}\right|$ & 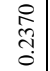 & $\begin{array}{l}m \\
\stackrel{0}{0} \\
0\end{array}$ & 总 \\
\hline \multicolumn{2}{|c|}{ Fi } & $\begin{array}{l}\infty \\
\stackrel{N}{2}\end{array}$ & 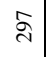 & $\mid \begin{array}{l}0 \\
\text { N }\end{array}$ & సิ & 怘 & $\hat{\text { N }}$ & के & 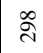 \\
\hline \multicolumn{2}{|c|}{ 受害 } & -1 & $\sim$ & $n$ & $\nabla$ & n & 0 & ^ & $\infty$ \\
\hline
\end{tabular}

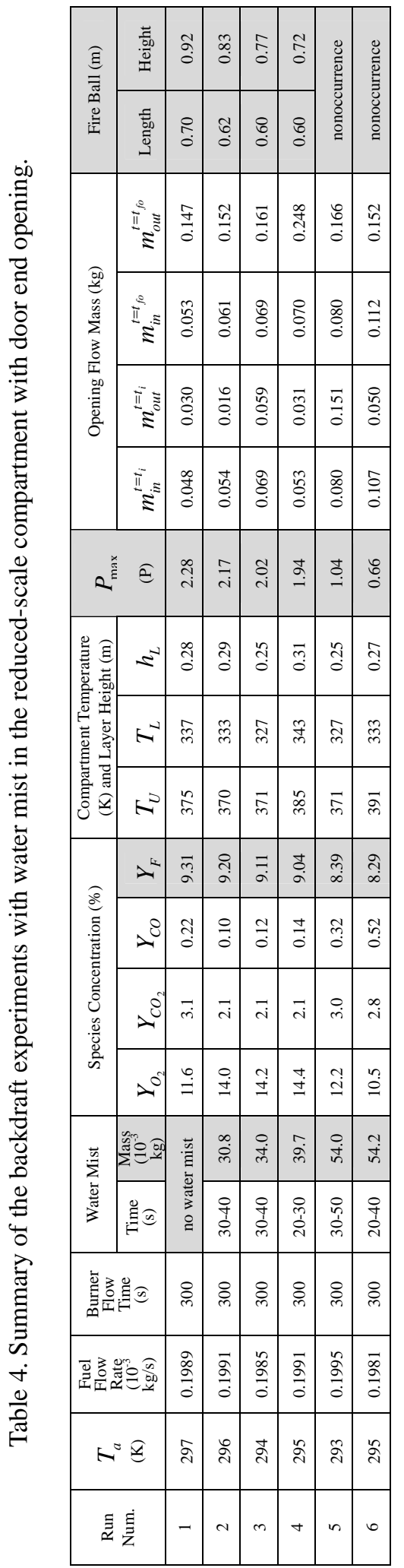


the compartment, respectively.

From Table 1, it is the first view that the relationship between the mass fractions of $\mathrm{O}_{2}$, $\mathrm{CO}_{2}$ and $\mathrm{CO}$, the upper temperature, the lower temperature and the layer height, the total mass which flows into and out of the compartment, and the occurrence of backdraft are fuzzy. This table shows that the peak pressure and the size of fire ball, which indicate the intensity of backdraft, increases with the increase of the mass fraction of unburned fuel. So the mass fraction of unburned fuel is a key parameter determining the occurrence of backdraft. And the more mass fraction of unburned fuel, the more intensity of backdraft. This conclusion can also be seen from experimental results with other seven opening geometries [18].

\section{Discussions with Opening Geometries}

Comparing the different opening geometries, the critical values of the mass fraction of unburned fuels are different. Figure 4 shows the mass fraction of unburned fuels determining the occurrence (solid) and nonoccurrence (hollow) of backdraft for eight opening geometries. Table 2 gives the corresponding estimated critical values for the occurrence of backdraft. These differences for eight opening geometries are the area of the opening and its location. From Fig. 4 and Table 2, the first impression is that the critical values of the ceiling openings are lower than for the end openings. Among the downside-slot end opening, the middle-slot end opening, the upside-slot end opening and the slot ceiling opening, whose opening area are the same, but locations are different, the critical value for the slot ceiling opening is the lowest and that of the downside-slot end opening is the highest. The higher the location of the center of the openings, the lower is the critical value of the mass fraction of unburned fuels. For the middle-slot end opening and the vertical middle-slot end opening, provided they have the same opening area and location of their center (i.e., both in the middle of the end wall, only one is horizontal and another is vertical), the critical value of the mass fraction of unburned fuel with a horizontal opening is lower than that of a vertical opening. So it is concluded that it is more difficult for backdraft to take place in the compartment with a vertical opening than that with a horizontal opening of the same opening area and location of their center. Comparing the middle-slot end opening with the window end opening, whose opening locations are the same, but the opening area of the former is bigger than that of the latter, the corresponding critical values of the mass fraction of unburned fuels are inverse. It is clear that with a larger opening area at the same location of its center, the critical value of the mass fraction of unburned fuel is lower. The same conclusion is also drawn from comparing the slot ceiling opening with the window ceiling opening. But the critical 
values for the window end opening and the vertical middle-slot end opening, whose location centers have the same location, are approximately the same, in spite of the different opening areas. The critical value for the door end opening is lower than that for the window end opening and the vertical middle-slot end opening.
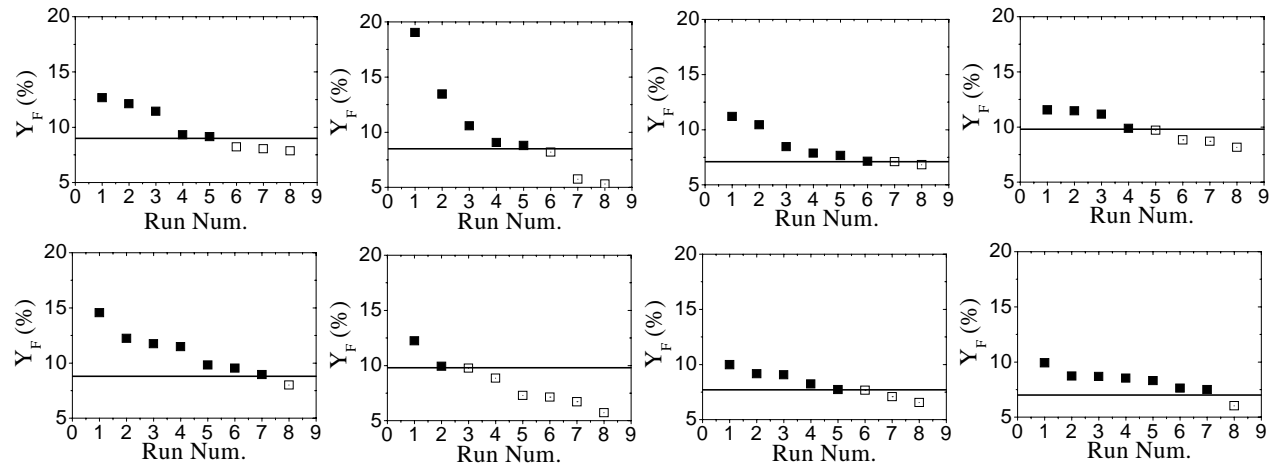

Fig. 4. The mass fractions of unburned fuels determining the occurrence (solid) and nonoccurrence (hollow) of backdraft with (a) downside-slot end opening, (b) middle-slot end opening, (c) upside-slot end opening, (d) window end opening, (e) door end opening, (f) vertical middle-slot end opening, (g) window ceiling opening, and (f) slot ceiling opening (from top to bottom and from left to right).

From the observation of large numbers of experiments, it can be concluded that gravity current prior to backdraft leads to the differences of the critical values of the mass fraction of unburned fuels determining the occurrence of backdraft among different opening geometries. Because of the invisible fresh air and hot gas, which constitute gravity current, the experimental results of scaled salt water experiments using flow visualization and DPIV help us interpret this [17]. In these salt water experiments, fresh water added with phenolphthalein simulated the hot gas, and salt water added with sodium hydroxide simulated the fresh water. Once phenolphthalein mixes with sodium hydroxide, the product of the reaction is red. The experimental detail was described in the literature [17]. Table 3, taken as an example, gives the average value of the nondimensional velocity $v^{*}=v / \sqrt{\beta g h_{1}}$, the nondimensional height $h^{*}=h_{0} / h_{1}$ and the nondimensional mass $m^{*}=v^{*} * h^{*}$ of gravity current for the downside-slot end opening, the middle-slot end opening and the upside-slot end opening. Here $v, \beta, h_{0}, h_{1}, g$ are the velocity, the density difference, the height of gravity current, the height of compartment, and the acceleration of gravity, respectively. It is obvious that the higher the opening location, the less is the mass of gravity current, which indicates that the less air enters the compartment in backdraft experiments, so the less hot gas leaves 
the compartment from the mass balance theory. And then the higher the opening location, the less unburned fuel moves out of opening, so the lower critical value of the mass fraction of unburned fuel determining the occurrence of backdraft.

Table 2. The estimated critical values of the mass fraction of unburned fuel determining the occurrence of backdraft for eight opening geometries.

\begin{tabular}{ll}
\hline Openings & Critical values (\%) \\
\hline downside-slot end opening & 9.0 \\
middle-slot end opening & 8.5 \\
upside-slot end opening & 7.1 \\
window end opening & 9.8 \\
door end opening & 8.8 \\
vertical middle-slot end & 9.8 \\
opening & \\
window ceiling opening & 7.7 \\
slot ceiling opening & 7.0 \\
\hline
\end{tabular}

\section{Mitigation Mechanism of Water Mist}

Table 3. Average values of $\bar{v}^{*}, \bar{h}^{*}$ and $\bar{m}^{*}$ for the downside-slot end opening, the middle-slot end opening and the upside-slot end opening.

\begin{tabular}{cccc}
\hline & $\begin{array}{c}\text { downside-sl } \\
\text { ot end } \\
\text { opening }\end{array}$ & $\begin{array}{c}\text { middle-slot } \\
\text { end } \\
\text { opening }\end{array}$ & $\begin{array}{c}\text { upside-slot } \\
\text { end } \\
\text { opening }\end{array}$ \\
\hline $\bar{V}^{*}$ & 0.48 & 0.45 & 0.40 \\
$\bar{h}^{*}$ & 0.43 & 0.44 & 0.48 \\
$\bar{m}^{*}$ & 0.206 & 0.198 & 0.192 \\
\hline
\end{tabular}

31 experimental results with water mist mitigating backdraft in a compartment with eight opening geometries are seen in Ref. [18]. This paper only gives the experimental results with the door end opening, as shown in Table 4. The results that the mass fraction of unburned fuel is a key parameter determining the occurrence of backdraft, and the more mass fraction of unburned fuel, the more intensity of backdraft can be seen in Column $Y_{F}, P_{\max }$ and fire ball size. In addition, from Table 4, it is indicated that the injection of water mist results in the decrease of the mass fraction of unburned fuel, but not the decrease of temperature in compartment including the upper temperature and the lower temperature. The mass fraction of unburned fuel in the experiment without water mist is the maximum value in all of the experiments. The more the water mist injection mass, the less mass fraction of unburned fuel, and the less intensity of backdraft. More water mist makes backdraft be from occurrence to nonoccurrence. Therefore, water mist is an effective mitigating tactic that is able to suppress backdraft in a compartment primarily by means of diluting the gas in the compartment and reducing the mass fraction of unburned fuel, rather than by a thermal mechanism of cooling. The same conclusions can be drawn from experimental results with other seven opening geometries. 


\section{CONCLUSIONS}

This paper reports the results of backdraft experiments in a reduced-scale compartment with eight opening geometries. This study shows that the mass fraction of unburned fuel (i.e., the unburned methane in this study) is a key parameter determining the occurrence of backdraft. As the mass fraction of unburned fuel increases, the over-pressure in the compartment also increases and the backdraft becomes more severe. In addition, the effects of eight opening geometries on the occurrence of backdraft are discussed. The results show that the critical values of the mass fraction of unburned fuel determining the occurrence of backdraft vary with different opening geometries.

The experimental results of water mist mitigating backdraft in a compartment are also given in this paper, and the mitigation mechanism is discussed. Water mist is an effective mitigating tactic able to suppress backdraft in a compartment primarily by means of diluting the gas in the compartment and reducing the mass fraction of unburned fuel, rather than by a thermal mechanism of cooling. The more the water mist injection mass, the less mass fraction of unburned fuel, and the less intensity of backdraft.

\section{ACKNOWLEDGMENTS}

The authors would like to acknowledge the support provided by the National Natural Science Foundation of China (Grant No. 50306024) and the China NKBRSF project (No. 2001CB409600).

\section{REFERENCES}

[1] Bukowski, R.W., "Modeling Backdraft: the Fire at 62 Watts Street,” NFPA Journal, 1995, 89: 85-89.

[2] Fleischmann, C.M., "Backdraft Phenomenon,” National Institute of Standards and Technology, USA, NIST-GCR-94-646, 1994.

[3] Fleischmann, C.M., Pagni, P.J., and Williamson, R.B., "Quantitative Backdraft Experiments," Fire Safety Science-Proceedings of the Forth International Symposium, International Association for Fire Safety Science, 1994: 337-348.

[4] Fleischmann, C.M., Pagni, P.J., and Williamson, R.B., "Salt Water Modeling of Fire Compartment Gravity Currents," Fire Safety Science-Proceedings of the Forth International Symposium, International Association for Fire Safety Science, 1994: 253-264.

[5] Fleischmann, C.M., and McGrattan, K.B., "Numerical and Experimental Gravity Currents Related to Backdrafts," Fire Safety Journal, 1999, 33: 21-34.

[6] Bolliger, I.B., "Full Residential-scale Backdraft,” University of Canterbury, New 
Zealand, Fire Engineering Research Report 95/1, 1995.

[7] Gojkovoc, D., “Initial Backdraft Experiments,” Lund University, Sweden, Report 3121, 2001.

[8] Gottuk, D.T., Williams, F.W., and Farley, J.P., "The Development and Mitigation of Backdrafts: a Full-scale Experimental Study,” Fire Safety Science-Proceedings of the Fifth International Symposium, International Association for Fire Safety Science, 1997: 935-946.

[9] Gottuk, D.T., Peatross, M.J., Farley, J.P., and Williams, F.W., “The Development and Mitigation of Backdraft: a Real-scale Shipboard Study,” Fire Safety Journal, 1999, 33: 261-282.

[10] Williams, F.W., Farley, J.P., Peatross, M.J., and Gottuk, D.T., "1995 Class B Firefighting Doctrine and Tactics: Final Report,” Naval Research Laboratory, USA, NRL/MR/6180-97-7909, 1997.

[11] Weng, W.G., and Fan, W.C., "Critical Condition of Backdraft in Compartment Fires: a Reduced-scale Experimental Study," Journal of Loss Prevention in the Process Industries, 2003, 16: 19-26.

[12] Weng, W.G., Fan, W.C., et al. "Experimental Study of Back-draft in a Compartment with Openings of Different Geometries,” Combustion and Flame, 2003, 132: 709-714.

[13] Weng, W.G., and Fan, W.C., "Experimental Study on the Mitigation of Backdraft in Compartment Fires with Water Mist,” Journal of Fire Sciences, 2002, 20: 259-278.

[14]Weng, W.G., and Fan, W.C., "Mitigation of Backdraft with Water Mist: a Reduced-scale Experimental Study,” Process Safety Progress, 2003, 22: 163-168.

[15] Weng, W.G., and Fan, W.C., "Nonlinear Analysis of the Backdraft Phenomenon in Room Fires,” Fire Safety Journal, 2004, 39: 447-464.

[16] Yang, R., Weng, W.G., Fan, W.C., et al. "Subgrid Scale laminar Flamelet Model for Partially Premixed Combustion and its Application to Backdraft Simulation,” Fire Safety Journal, 2005, 40: 81-98.

[17] Weng, W.G., Fan, W.C., et al. "Study on Salt Water Modeling of Gravity Currents prior to Backdrafts using Flow Visualization and DPIV,” Experiments in Fluids, 2002, 33: 398-404.

[18] Weng, W.G., A Simulative Study on Backdraft Phenomenon in Compartment Fires, Ph. D dissertation, University of Science and Technology of China, 2002.

[19] Quintiere, J.G., Steckler, K., and Corley, D., “An Assessment of Fire Induced Flows in Compartments,” Fire Science and Technology, 1984, 4: 1-14.

[20] McCaffrey, B.J., and Heskestand, G., “A Robust Bidirectional Low-velocity Probe for Flame and Fire Application,” Combustion and Flame, 2: 6125-6127. 